Supporting Information

\title{
A metal-free electro-activated sulfite process for As(III) oxidation in water using graphite electrodes
}

Tao Luo ${ }^{\dagger}$, Ying Peng ${ }^{\dagger}$, Long Chen ${ }^{\ddagger}$, Jinjun $\mathrm{Li}^{\dagger}$, Feng Wu* ${ }^{*}$, Danna Zhou ${ }^{\star}$

† School of Resources and Environmental Science, Wuhan University, Wuhan, 430079, P. R. China

‡ Department of Civil and Environmental Engineering, Northeastern University, Boston, MA, USA

$\S$ Faculty of Material Science and Chemistry, China University of Geosciences, Wuhan, 430074, P. R. China

Corresponding Authors

Danna Zhou, e-mail: zdncug@163.com.

Feng Wu, e-mail: fengwu@whu.edu.cn.

$$
\begin{gathered}
28 \text { pages } \\
8 \text { texts } \\
21 \text { figures } \\
3 \text { tables }
\end{gathered}
$$




\section{Text S1 The reaction between ${ }^{1} \mathrm{O}_{2}$ and $\mathrm{As}$ (III)}

To test the possibility of $\mathrm{As}$ (III) oxidation caused by ${ }^{1} \mathrm{O}_{2}$, a ${ }^{1} \mathrm{O}_{2}$ generation system consisted with visible light (wavelength $640 \mathrm{~nm}$ ) and methylene blue $\left(\mathrm{MB}^{+}\right)$was used. ${ }^{1} \mathrm{MB}^{+}$was used as sensitizer to generate ${ }^{1} \mathrm{O}_{2}$. The reactor setup was shown in Fig. S3. The reaction solution contained $10 \mathrm{mM}$ phosphate buffer (pH 7), $5 \mathrm{mg} \mathrm{L}^{-1} \mathrm{MB}, 5 \mu \mathrm{M}$ As(III) or $10 \mu \mathrm{M}$ FFA. In this experiment, FFA was used as a reference chemical to demonstrate reactivity of As(III) toward ${ }^{1} \mathrm{O}_{2 .}{ }^{2}$

\section{Text $\mathrm{S} 2$ Determination of second-order rate constants $\left(\mathrm{kAs}_{\mathrm{AIII}}, \mathrm{SO}_{5}\right)$}

To determine the rate constant for the reaction between $\mathrm{SO}_{5}{ }^{-}$and $\mathrm{As}(\mathrm{III})$, competitive kinetic method was used. ${ }^{3}$ p-benzenediol was used as the competitive reagent for $\mathrm{SO}_{5}{ }^{--}$, but it is not stable during electrolysis (data not given). According to our previous work, ${ }^{4} \mathrm{Fe}(\mathrm{III})$-sulfite system was employed for the competitive experiment. $\mathrm{N}$-hexanol was used to scavenge $\mathrm{SO}_{4}{ }^{-}$and $\mathrm{HO} \cdot$ and avoid their reactions with p-benzenediol or As(III). A $500 \mathrm{~mL}$ reaction solution containing $0.1 \mathrm{mM} \mathrm{Fe}(\mathrm{III}), 1 \mathrm{mM}$ sulfite, $5 \mu \mathrm{M} \mathrm{As}$ (III), $5 \mathrm{mM}$ N-hexanol, and $10 \mu \mathrm{M}$ p-benzenediol was prepared and the $\mathrm{pH}$ was adjusted to 7 with diluted $\mathrm{H}_{2} \mathrm{SO}_{4}$ and sulfite stock solution. In different time intervals, samples were withdrawn to determine $\mathrm{As}(\mathrm{III})$ and p-benzenediol concentration, separately.

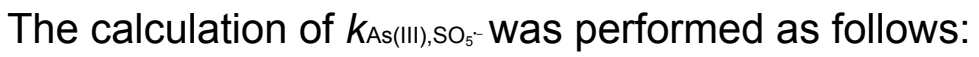

$$
\begin{aligned}
& r_{\mathrm{p} \text {-benzenediol, } \mathrm{SO}_{5^{-}}}=k_{\mathrm{p} \text {-benzenediol, } \mathrm{SO}_{5^{-}}}\left[\mathrm{SO}_{5}{ }^{-}\right]_{\mathrm{ss}}[\mathrm{p} \text {-benzenediol }]_{0} \\
& r_{\mathrm{As}(\mathrm{III}), \mathrm{SO}_{5^{-}}}=k_{\mathrm{As}(\mathrm{III}), \mathrm{SO}_{5^{-}}}\left[\mathrm{SO}_{5^{\circ-}}\right]_{\mathrm{ss}}[\mathrm{As}(\mathrm{III})]_{0} \\
& K_{\mathrm{As}(\mathrm{III}), \mathrm{SO}_{5^{-}}}=\frac{k_{\mathrm{p}-\text { benzenediol }, S O_{5}^{\circ-}}[\mathrm{p}-\text { benzenediol }]_{0} \mathrm{r}_{\mathrm{As}(\mathrm{III}), S 0_{5}^{--}}}{[\mathrm{As}(\mathrm{III})]_{0} \mathrm{r}_{\mathrm{p}-\text { benzenediol }, S O_{5}^{\circ-}}}
\end{aligned}
$$

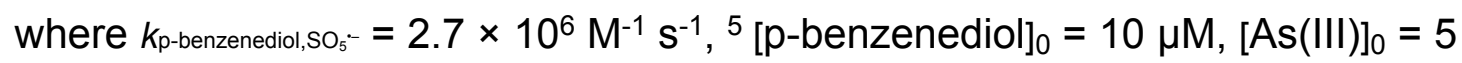


$\mu \mathrm{M}, r_{\mathrm{p} \text {-benzenedio, } \mathrm{SO}_{5^{-}}}$and $r_{\mathrm{As}(\mathrm{III}), \mathrm{SO}_{5}{ }^{-}}$were calculated to be $0.875 \mathrm{~min}^{-1}$ and $0.194 \mathrm{~min}^{-1}$, respectively, with the data of completive reactions (Fig. S16). As a result, $k_{\mathrm{As}(\mathrm{III}), \mathrm{SO}_{5^{-}}}=1.2 \times 10^{6} \mathrm{M}^{-1} \mathrm{~s}^{-1}$ was obtained according to equation S3.

\section{Text S3 Determination of S(IV) by ion chromatography (IC)}

An IC-930 ion chromatograph system (Metrohm, Switzerland) equipped with a anion column (metrosep A supp 5-250/4.0) was employed to determine the S(IV) concentration at different reaction times. A mixed solution of $3.2 \mathrm{mM} \mathrm{Na}_{2} \mathrm{CO}_{3}$, $6 \mathrm{mM} \mathrm{NaHCO}_{3}$ and $5 \%$ acetone was used as the eluent and the flow rate was set at $1.0 \mathrm{~mL} \mathrm{~min}-1$. Formaldehyde $(0.01 \%)$ was added into the samples to prevent further oxidation of S(IV) with oxygen.

\section{Text S4 Determination of FFA and p-benzenediol by HPLC}

A LC-10A HPLC system (Shimadzu, Japan) equipped with a C18 column (Kromasil 100-5) was used to determine the FFA and p-benzenediol, respectively. The mobile phase was an $85: 15(\mathrm{v} / \mathrm{v})$ mixture of $0.1 \%$ phosphoric acid and methanol for FFA analysis. And for $p$-benzenediol, a mixture of methanol and $0.2 \%$ acetic acid with 50:50 (v/v) was used. The flow rate for both mobile phases was $1.0 \mathrm{~mL} \mathrm{~min}-1$. The wavelength of UV detector was set at $218 \mathrm{~nm}$ and $277 \mathrm{~nm}$ for FFA and p-benzenediol, respectively.

\section{Text S5 Speciation of As(III) and As(V)}

Liquid chromatography-hydride generation-atomic fluorescence spectrometry (LC-HG-AFS) was applied to arsenic speciation. A LC-10A (Shimadzu, Japan) liquid chromatograph coupled with a Bohui RGF-6200 atomic fluorescence spectrometer (Beijing, China) was used to determine As(III) and As(V) 
simultaneously. Phosphate buffer $(45 \mathrm{mM}, \mathrm{pH} 5.6)$ as mobile phase and a Hamilton PRP-X100 anion-exchange column (Reno, USA) were used to separate $\mathrm{As}(\mathrm{III})$ and $\mathrm{As}(\mathrm{V}) .5 \% \mathrm{HCl}-2 \% \mathrm{KBH}_{4}$ solutions were used as reducing reagent for HG-AFS. Argon (99.99\%) was used as the carrier gas and shielding gas during the determination.

\section{Text S6 Scanning electron microscopy (SEM) of electrode}

The surface morphological changes of graphite electrodes before and after electrolysis were evaluated with SEM (EM-30 PLUS, COXEM, South Korea). SEM images were obtained with the excitation energy of $20 \mathrm{KV}$.

\section{Text S7 Economic analysis of different systems for As(III) oxidation}

A simple economic analysis using the electrical energy per order $(E E / O)$ index was performed to evaluate energy and chemicals consumption. ${ }^{6} \mathrm{EE} / \mathrm{O}$ is defined as the number of electrical energy required for oxidizing As(III) by one order of magnitude in $1 \mathrm{~L}$ of contaminated water. The overall EE/O can be expressed as eq. S4.

$\mathrm{EE} / \mathrm{O}=\frac{(P / V)+\alpha[\text { oxidant }]}{\log \left(\frac{C_{0}}{c_{i}}\right)}$

Where, $P N$ is the energy input with the unit of $\mathrm{kWh} \mathrm{L}^{-1}$; [oxidant] is the working concentration of oxidant; $\alpha$ is the unit convertor to translate oxidant amount to energy unit (i.e., $1.5 \times 10^{-6} \mathrm{kWh} \mathrm{mg}^{-1}$ sulfite, $1.1 \times 10^{-5} \mathrm{kWh} \mathrm{mg}^{-1} \mathrm{H}_{2} \mathrm{O}_{2}, 5.3 \times$ $\left.10^{-6} \mathrm{kWh} \mathrm{mg}^{-1} \mathrm{PS}\right) . \mathrm{C}_{\mathrm{i}}$ and $\mathrm{C}_{0}$ are the final and the initial concentration of $\mathrm{As}(\mathrm{III})$, respectively.

The unit conversion is expressed as follows:

The price of $\mathrm{H}_{2} \mathrm{O}_{2}$ (50\% by weight) on Alibaba.com is $\$ 400$ per ton. Considering the average electricity cost is around 19 cent/kWh in China, one milligram of 
$\mathrm{H}_{2} \mathrm{O}_{2}$ can be converted to $4.21 \times 10^{-6} \mathrm{kWh}$. As for sulfite, the price of $\mathrm{Na}_{2} \mathrm{SO}_{3}$ on Alibaba.com is $\$ 285$ per ton. Hence, one milligram of $\mathrm{Na}_{2} \mathrm{SO}_{3}$ can be converted to $1.5 \times 10^{-6} \mathrm{kWh}$. As for persulfate (PS), the price of PS on Alibaba.com is $\$ 1000$ per ton. Hence, one milligram of PS can be converted to $5.3 \times 10^{-6} \mathrm{kWh}$.

In the ES process,

$\mathrm{EE} / \mathrm{O}=\frac{3 \mathrm{~W} \times 10^{-6} \times 40 \mathrm{~min} /(0.5 \mathrm{~L} \times 60)+1.5 \times 10^{-6} \mathrm{kWh}^{\frac{\mathrm{mg}}{126}} \times 1 \mathrm{mM}}{2}$

$=2.0 \times 10^{-6} \mathrm{kWh} \mathrm{L}^{-1}$

In the EO process,

$\mathrm{EE} / \mathrm{O}=\frac{3 \mathrm{~W} \times 10^{-6} \times 40 \mathrm{~min} /(0.5 \mathrm{~L} \times 60)}{\log \left(\frac{1}{0.7}\right)}$

$=2.6 \times 10^{-5} \mathrm{kWh} \mathrm{L}^{-1}$

In Lescano's work $7,40 \mathrm{~W}$ light and $0.125 \mathrm{mM} \mathrm{H}_{2} \mathrm{O}_{2}$ achieved $99 \%$ oxidation of $0.2 \mathrm{mg} \mathrm{L}^{-1} \mathrm{As}(\mathrm{III})$ within $15 \mathrm{~min}$. The EE/O = 4.6 $\times 10^{-2} \mathrm{kWh} \mathrm{L}^{-1}$.

In our previous work, ${ }^{8}$ the UVC-sulfite system was used to oxidize As(III) with a $5 \mathrm{~W}$ UVC lamp. $50 \%$ oxidation of $5 \mu \mathrm{M} \mathrm{As}$ (III) was achieved at $\mathrm{pH} 7$ with 2 $\mathrm{mM}$ sulfite within $10 \mathrm{~min}$. Thus, the EE/O $=1.4 \times 10^{-2} \mathrm{kWh} \mathrm{L}^{-1}$.

In Neppolian's work, $936 \mathrm{~W}$ ultrasound (US) and $0.2 \mathrm{mM}$ PS achieved completely oxidation of $0.04 \mathrm{mM}$ As(III) within $10 \mathrm{~min}$. Hence, the $\mathrm{EE} / \mathrm{O}=1.5 \times$ $10^{-2} \mathrm{kWh} \mathrm{L}^{-1}$.

In the Li's work, ${ }^{10}$ reduced graphene oxide electrodes employing $2.5 \mathrm{~V}(20 \mathrm{~mA})$ achieved $40 \% \operatorname{As}(\mathrm{III})$ oxidation within $60 \mathrm{~min}$ at $\mathrm{pH} 7.2$. The $\mathrm{EE} / \mathrm{O}=2.5 \times 10^{-4}$ $\mathrm{kWh} \mathrm{L}^{-1}$.

\section{Text S8 Calculation of current efficiency (CE)}

The current efficiency (CE) were calculated by Eq. S7 


$$
\mathrm{CE}=\frac{2 \Delta \mathrm{CFV}}{I t} \times 100 \%
$$

Where $\Delta \mathrm{C}$ represents the changes of $\mathrm{As}(\mathrm{III}), \mathrm{F}$ represents the Faraday constant $\left(96485 \mathrm{C} \mathrm{mol}^{-1}\right), \mathrm{V}$ represents the reaction volume $(\mathrm{L})$, I represents current $(A), t$ represents the reaction time (s).

In the ES process, As(III) was completely oxidized to $\mathrm{As}(\mathrm{V})$ in $40 \mathrm{~min}$, and the changes of current was shown in the Fig. S21. Hence, according to eq. S7, the current efficiency is expressed as:

$$
\begin{aligned}
\mathrm{CE}_{\mathrm{As}(\mathrm{III})}= & \frac{2 \times 5 \times 0.5 \times 96485 \times 10^{-6}}{3 \times 10^{-3} \times 5 \times 60+1 \times 10^{-3} \times 30 \times 60} \times 100 \% \\
& =17.9 \%
\end{aligned}
$$




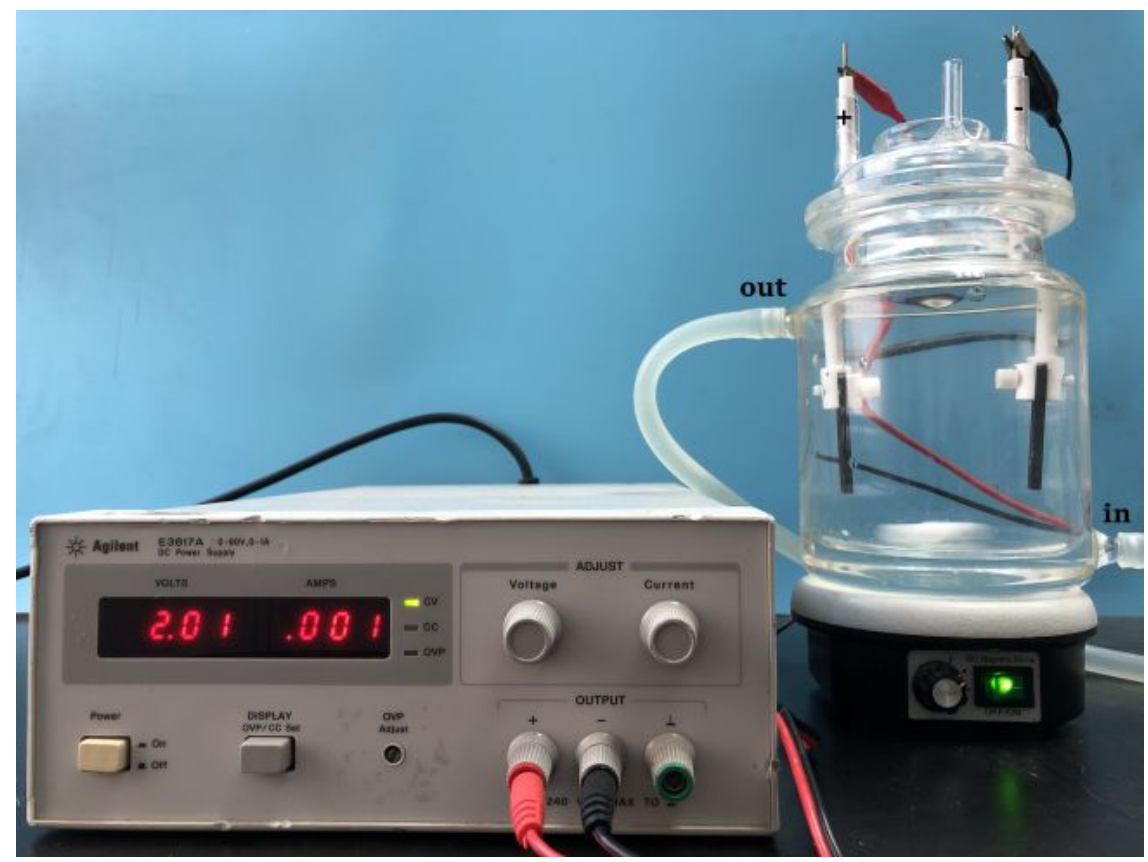

Fig. S1 Experimental setup with the one-compartment electrolysis cell used in the ES and EO processes.

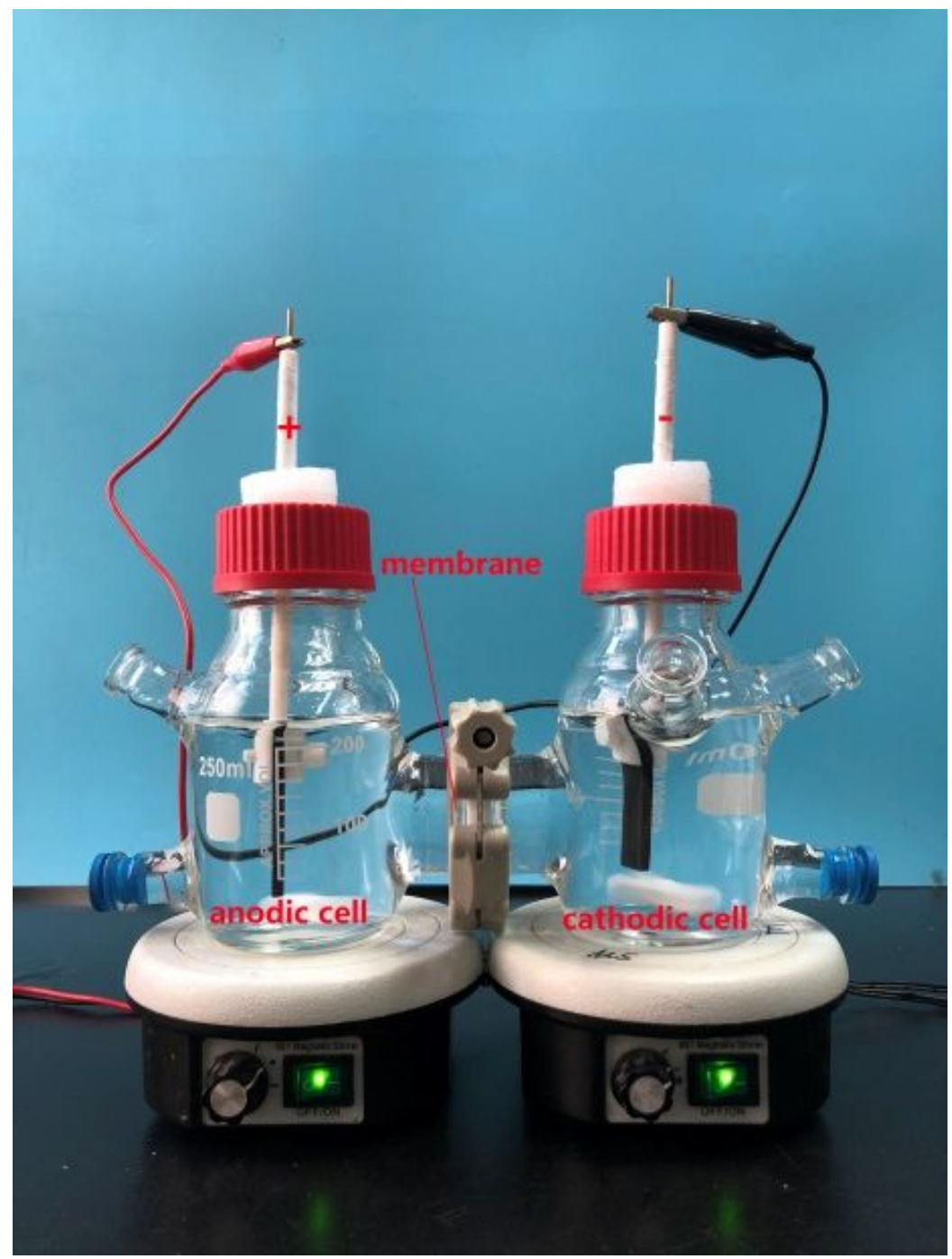


Fig. S2 Experimental setup with the two-compartment electrolysis cell used in the ES and EO processes.

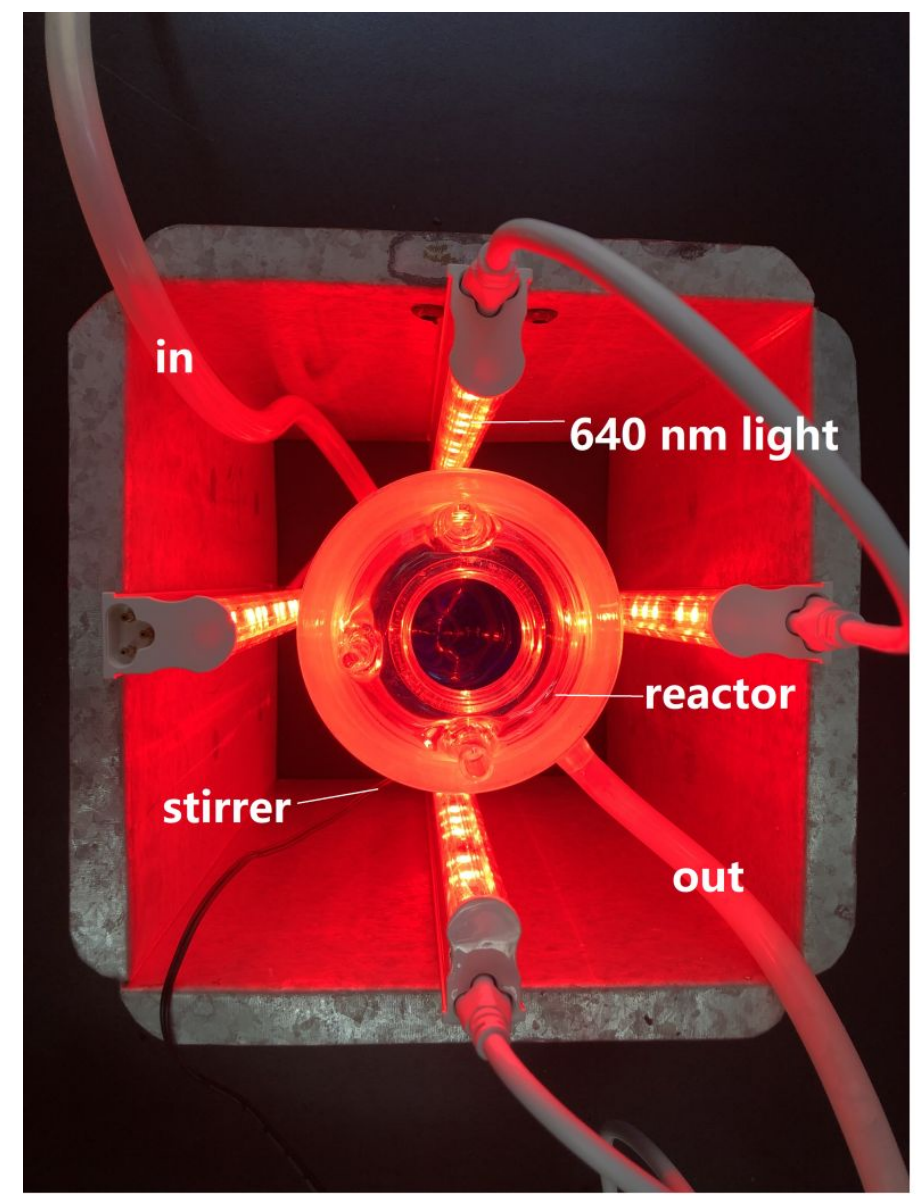

Fig. S3 The photochemical reactor setup for ${ }^{1} \mathrm{O}_{2}$ generation with the photosensitizer dye, methylene blue $\left(\mathrm{MB}^{+}\right)$, and irradiation with red LED lamps (wavelength $640 \mathrm{~nm}$ ). 


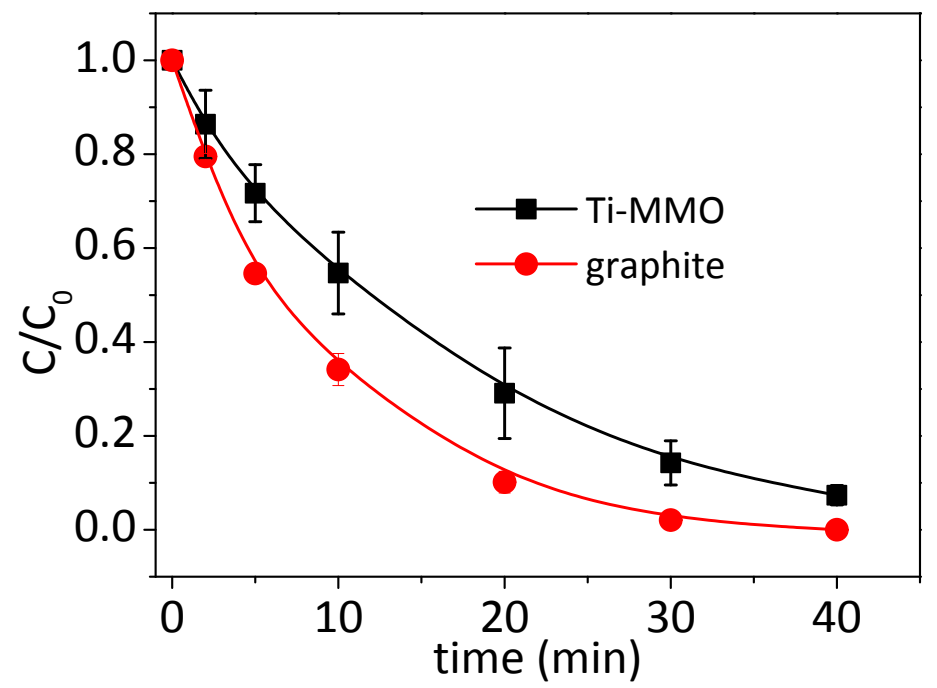

Fig. S4 As(III) oxidation in the ES process with different types of electrodes. Initial conditions: cell voltage $=2 \mathrm{~V},[\mathrm{~S}(\mathrm{IV})]=1 \mathrm{mM},[\mathrm{As}(\mathrm{III})]=5 \mu \mathrm{M}$, [phosphate buffer $]=10 \mathrm{mM}, \mathrm{pH} 7 .\left[\mathrm{Na}_{2} \mathrm{SO}_{4}\right]=0$ and $10 \mathrm{mM}$ for the graphite electrodes and the Ti-MMO electrodes, respectively. 


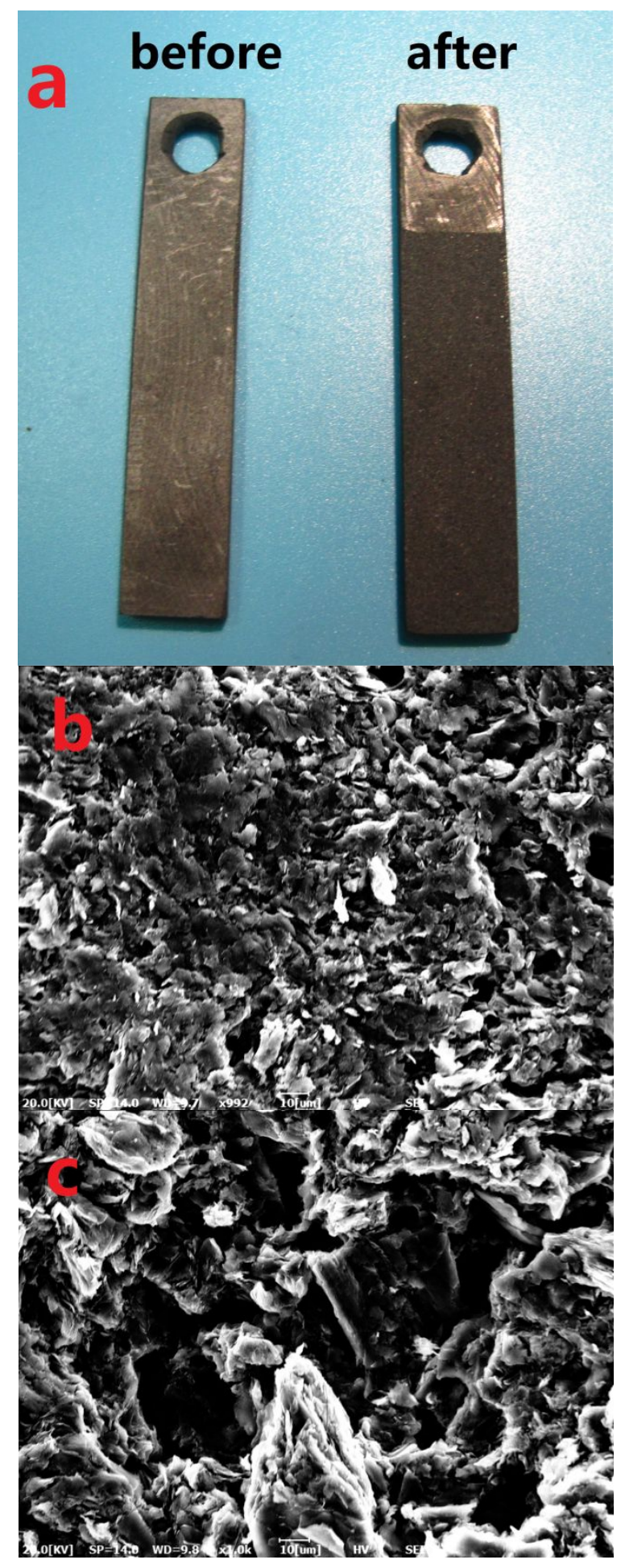

Fig. S5 (a) Comparsion of anodic electrode before and after use, SEM images of (b) new electrode and (c) anodic electrode used for long time. The electrode before use appears bright, while it turns dark after use (a). The color change can be a result of enhanced surface roughness due to carbon corrosion occurred in reactions, which leads to light scattering. This is confirmed by the SEM images. The electrode surface was relatively smooth before use (b), and some holes are created on the surface after use (c). 

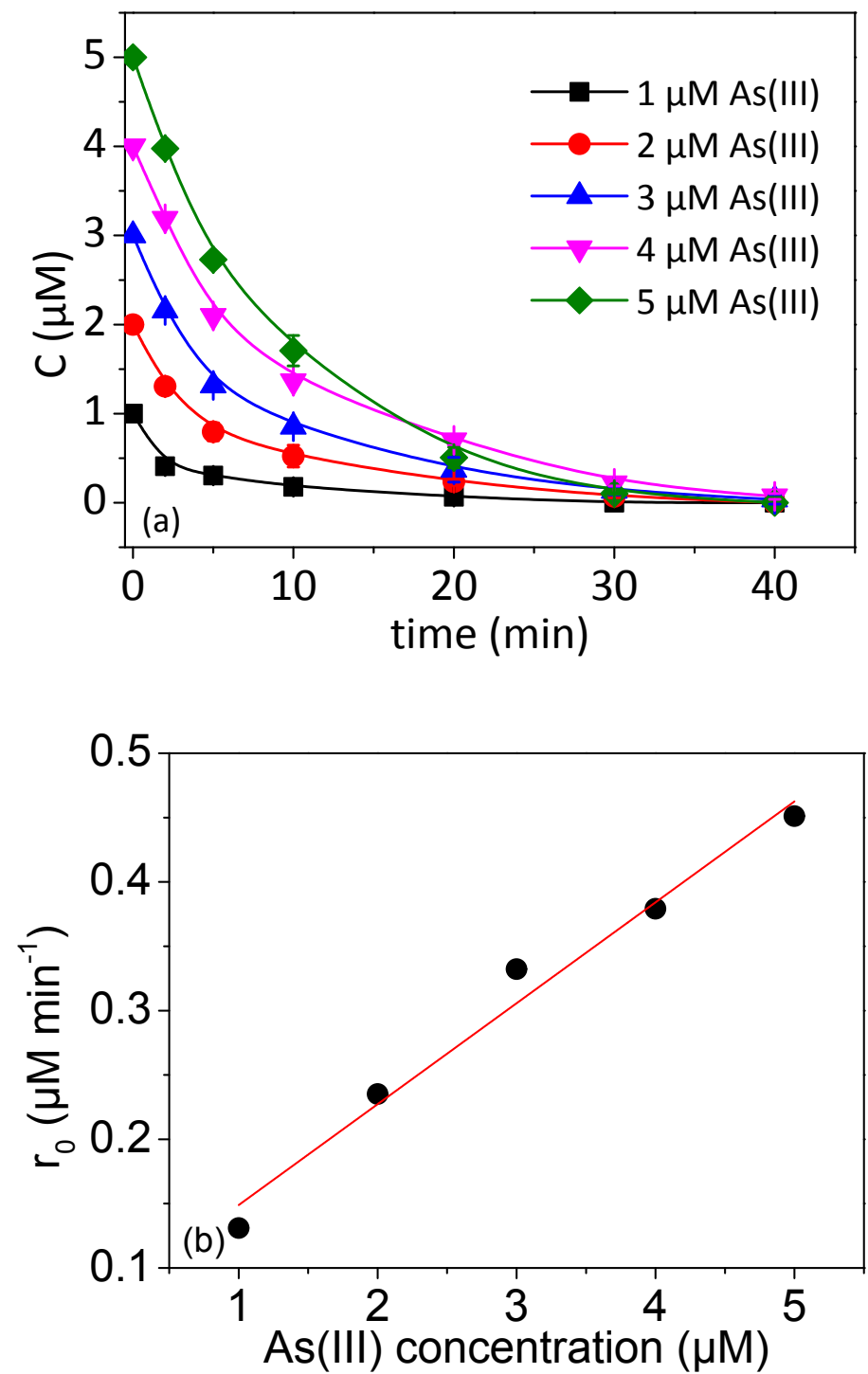

Fig. S6 (a) As(III) oxidation at various initial As(III) concentrations in the ES process and (b) the linear fit of the initial rate versus the initial As(III) concentration. Initial conditions: cell voltage $=2 \mathrm{~V},[\mathrm{~S}(\mathrm{IV})]=1 \mathrm{mM},[\mathrm{As}(\mathrm{III})]=$ 1-5 $\mu \mathrm{M}$, [phosphate buffer] $=10 \mathrm{mM}, \mathrm{pH}$ 7. The kinetic curve of $r_{0}$ versus $\mathrm{C}_{0}$ was plotted and fitted, where $r_{0}$ is the slopes of concentration decay curves within $5 \mathrm{~min}, \mathrm{C}_{0}$ is the initial concentration of $\mathrm{As}(\mathrm{III})$ in the reaction solution. The results of the linear fit of the data was acceptable in the range of 1-5 $\mu \mathrm{M} \mathrm{As}(\mathrm{III})$. 


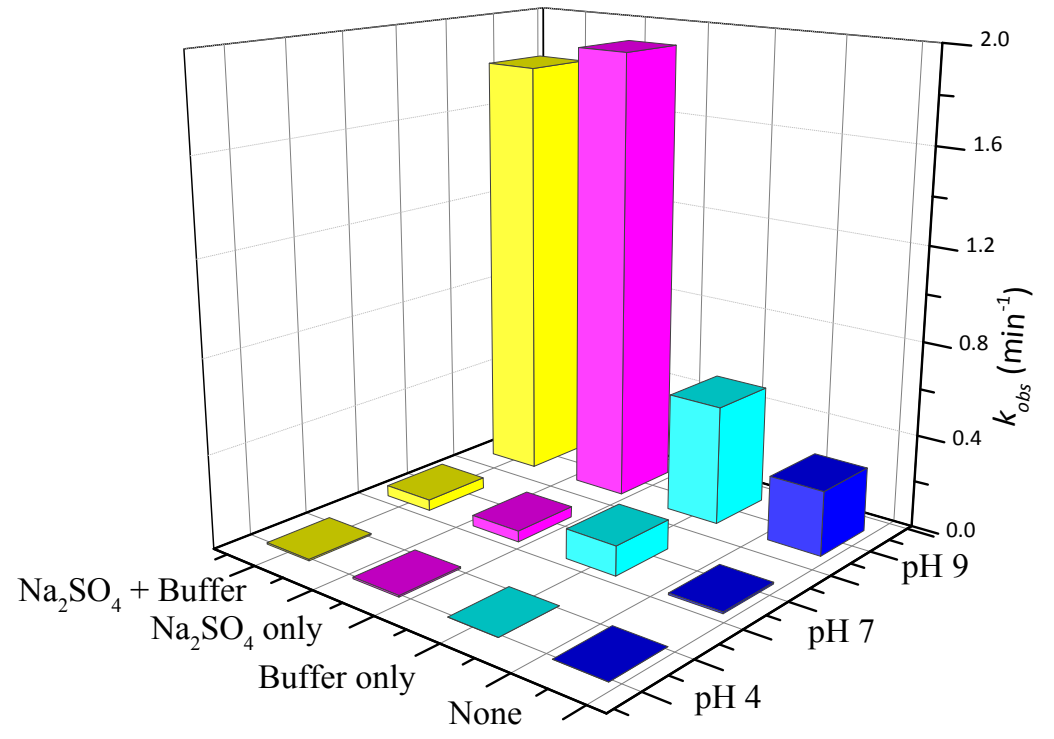

Fig. S7 Effects of different buffers for electro-sulfite system. Initial conditions: cell voltage $=2 \mathrm{~V},[\mathrm{~S}(\mathrm{IV})]=1 \mathrm{mM},[\mathrm{As}(\mathrm{III})]=5 \mu \mathrm{M},\left[\mathrm{Na}_{2} \mathrm{SO}_{4}\right]=0,50 \mathrm{mM}$, [acetate buffer, phosphate buffer, borate buffer] $=10 \mathrm{mM}, \mathrm{pH} 4,7,9$.

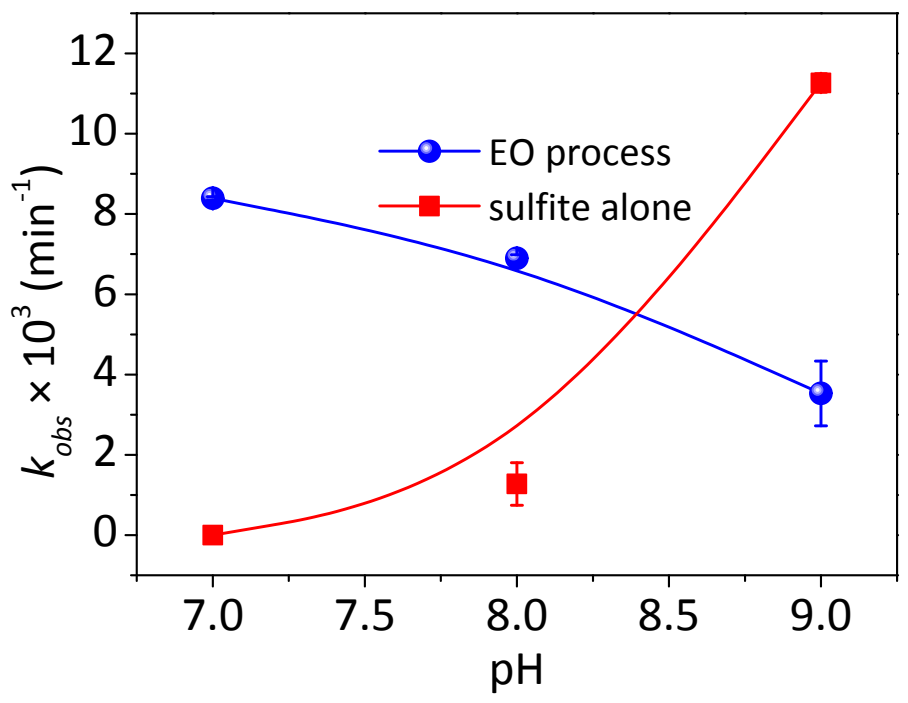

Fig. S8 Effect of pH on As(III) oxidation in the EO process or with sulfite alone. Initial conditions: cell voltage $=2 \mathrm{~V},[\mathrm{As}(\mathrm{III})]=5 \mu \mathrm{M},[\mathrm{S}(\mathrm{IV})]=1 \mathrm{mM}$, [phosphate buffer, borate buffer] $=10 \mathrm{mM}, \mathrm{pH} \mathrm{7,} \mathrm{8,} 9$. 

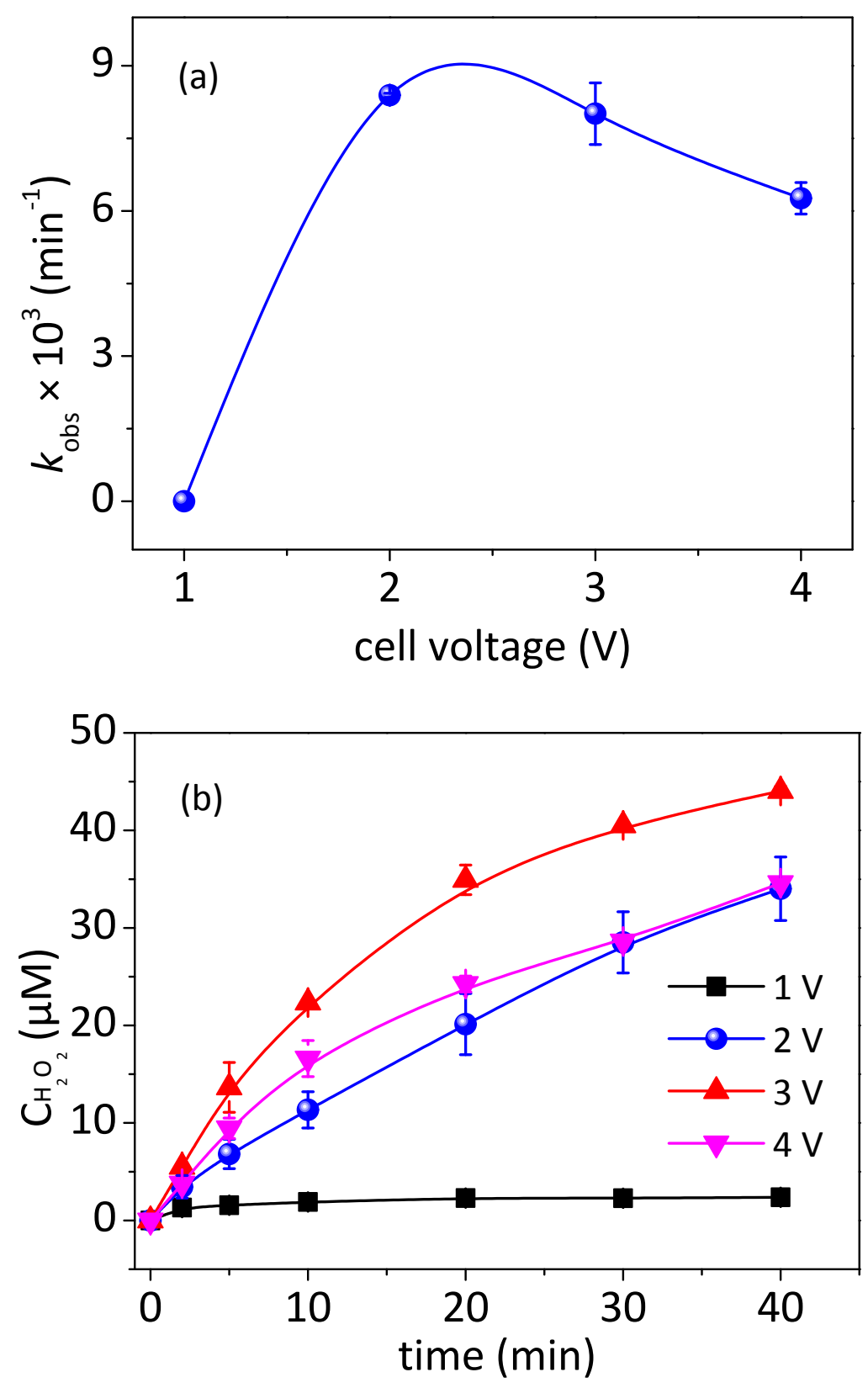

Fig. S9 (a) Effect of potential for As(III) oxidation in the EO process, (b) Concentrations of $\mathrm{H}_{2} \mathrm{O}_{2}$ in solutions in the EO process with different cell voltages. Initial conditions: cell voltage $=1-4 \mathrm{~V},[\mathrm{As}(\mathrm{III})]=5 \mu \mathrm{M}$ for $(\mathrm{a}),[\mathrm{DPD}]=$ $0.1 \mathrm{~g} \mathrm{~mL}^{-1},[P O D]=0.01 \mathrm{~g} \mathrm{~mL}^{-1}$, [phosphate buffer $]=10 \mathrm{mM}, \mathrm{pH} 7$. 


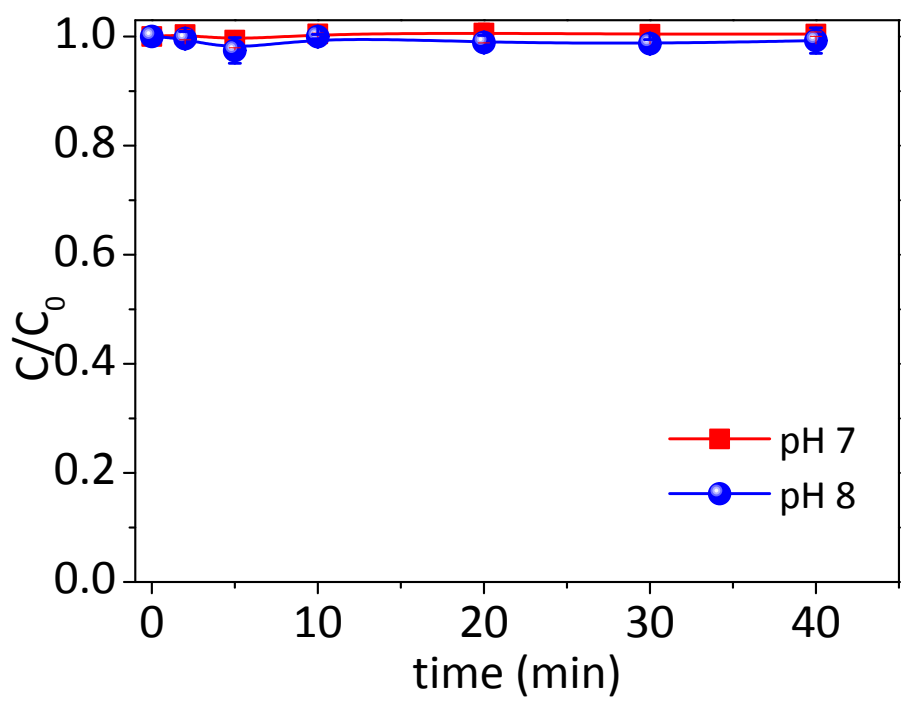

Fig. S10 Change of $\mathrm{As}(\mathrm{III})$ concentration in the solutions containing $\mathrm{H}_{2} \mathrm{O}_{2}$ without electrolysis. Initial conditions: $\left[\mathrm{H}_{2} \mathrm{O}_{2}\right]=40 \mu \mathrm{M},[\mathrm{As}(\mathrm{III})]=5 \mu \mathrm{M}$, [phosphate buffer] $=10 \mathrm{mM}, \mathrm{pH} 7,8$. 


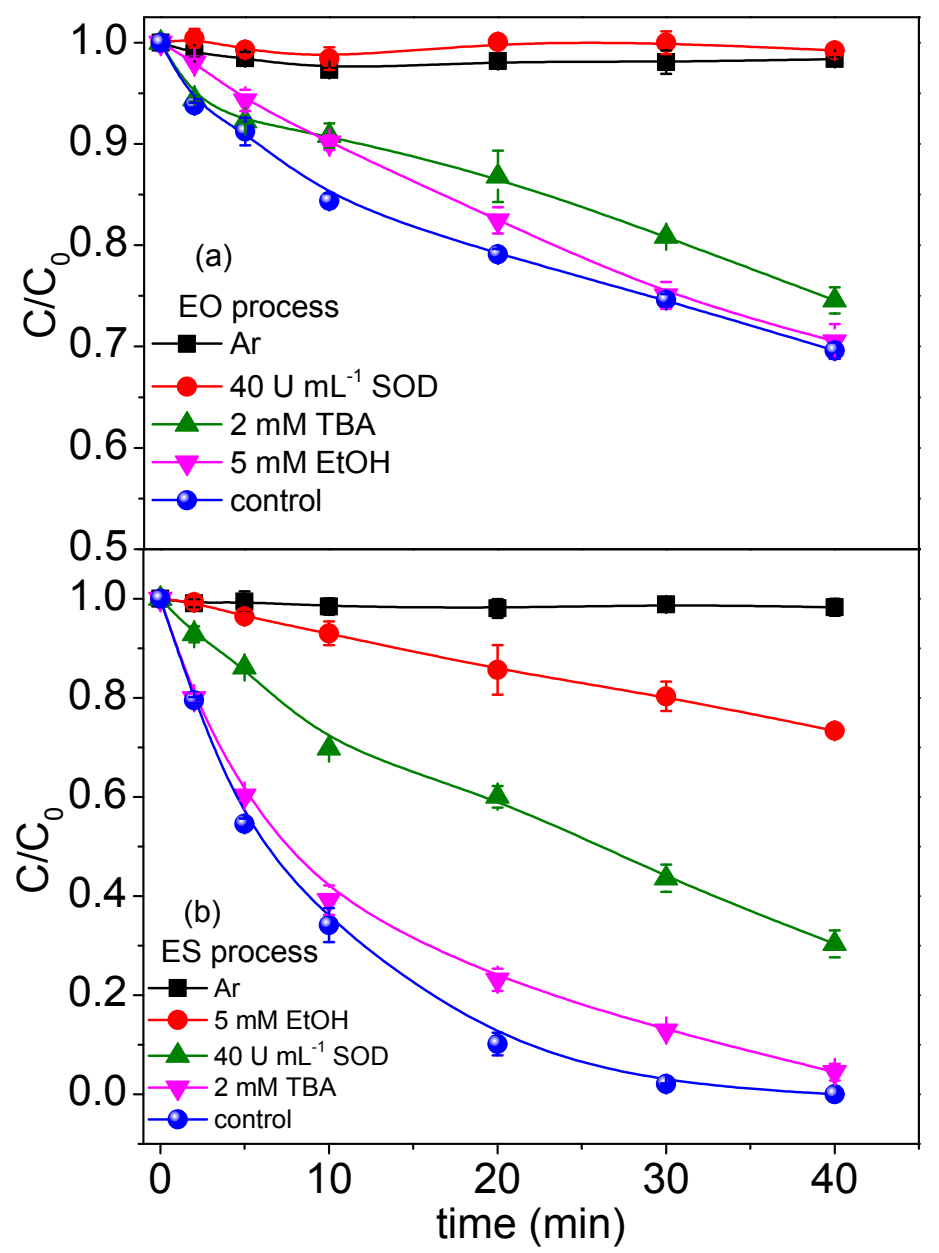

Fig. S11 Changes of As(III) concentration in (a) the EO process and (b) the ES process in the presence of different scavengers. Initial conditions: cell voltage $=2 \mathrm{~V},[\mathrm{~S}(\mathrm{IV})]=1 \mathrm{mM}$ for $(\mathrm{b}),[\mathrm{As}(\mathrm{III})]=5 \mu \mathrm{M},[\mathrm{SOD}]=40 \mathrm{U} \mathrm{mL}^{-1},[\mathrm{EtOH}]=5$ $\mathrm{mM},[\mathrm{TBA}]=2 \mathrm{mM}$, [phosphate buffer] $=10 \mathrm{mM}, \mathrm{pH}$. The flow rate of Ar was about $500 \mathrm{~mL} \mathrm{~min}^{-1}$. 


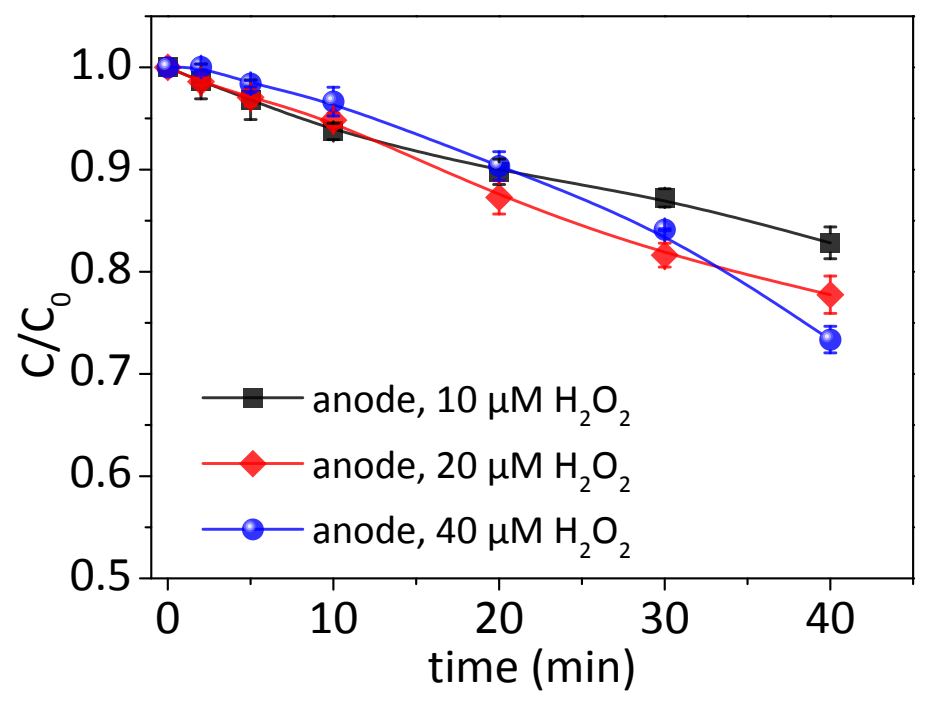

Fig. S12 As(III) oxidation in the presence of $\mathrm{H}_{2} \mathrm{O}_{2}$ in anodic compartment in the EO process. Initial conditions: $\left[\mathrm{H}_{2} \mathrm{O}_{2}\right]=10-40 \mu \mathrm{M},[\mathrm{As}(\mathrm{III})]=5 \mu \mathrm{M}$, [phosphate buffer] $=10 \mathrm{mM}, \mathrm{pH} 7$.

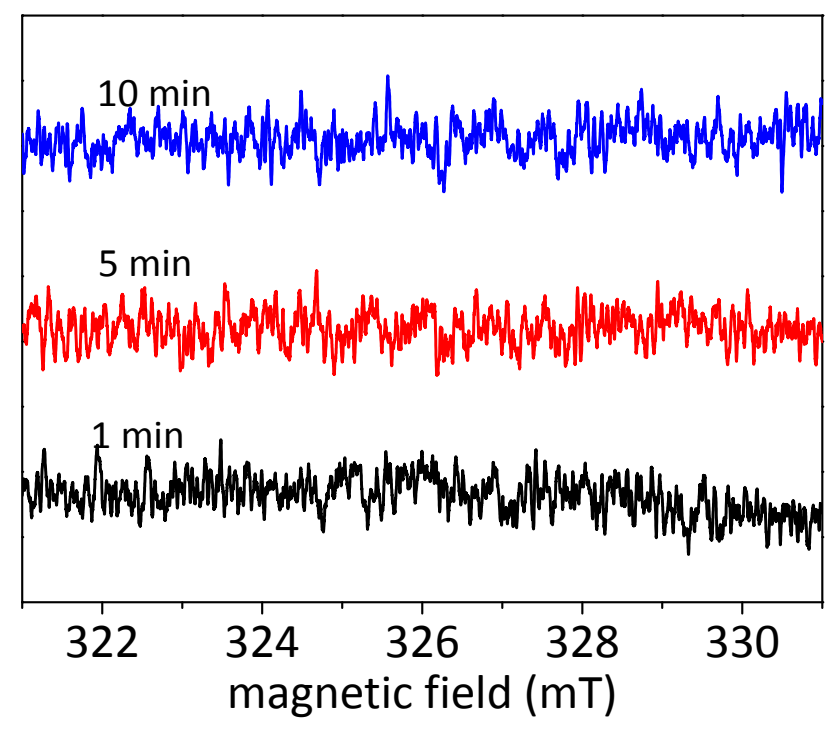

Fig. S13 ESR spectra with DMPO as spin trap for HO' radical in the EO process. Initial conditions: cell voltage $=2 \mathrm{~V},[\mathrm{DMPO}]=25 \mathrm{mM}$, [phosphate buffer $]=10$ $\mathrm{mM}, \mathrm{pH} 7$. 


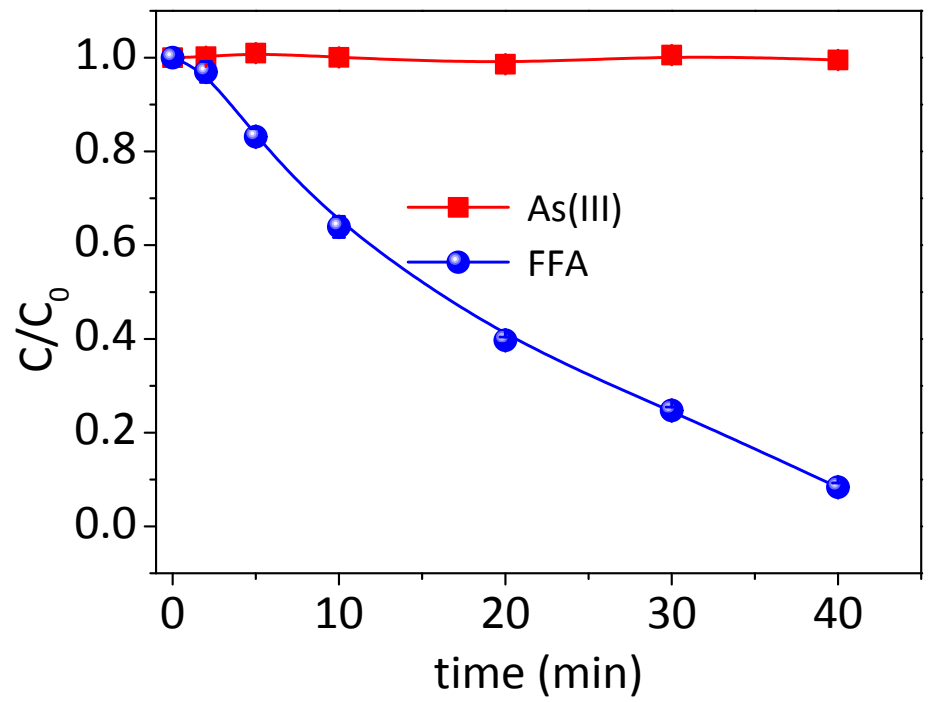

Fig. S14 Changes of As(III) and FFA concentrations in the visible light-MB ${ }^{+}$ system producing ${ }^{1} \mathrm{O}_{2}$. Initial conditions: $\left[\mathrm{MB}^{+}\right]=5 \mathrm{mg} \mathrm{L}^{-1},[\mathrm{As}(\mathrm{III})]=5 \mu \mathrm{M}$, [FFA] $=10 \mu \mathrm{M}$, [phosphate buffer $]=10 \mathrm{mM}, \mathrm{pH} 7$.

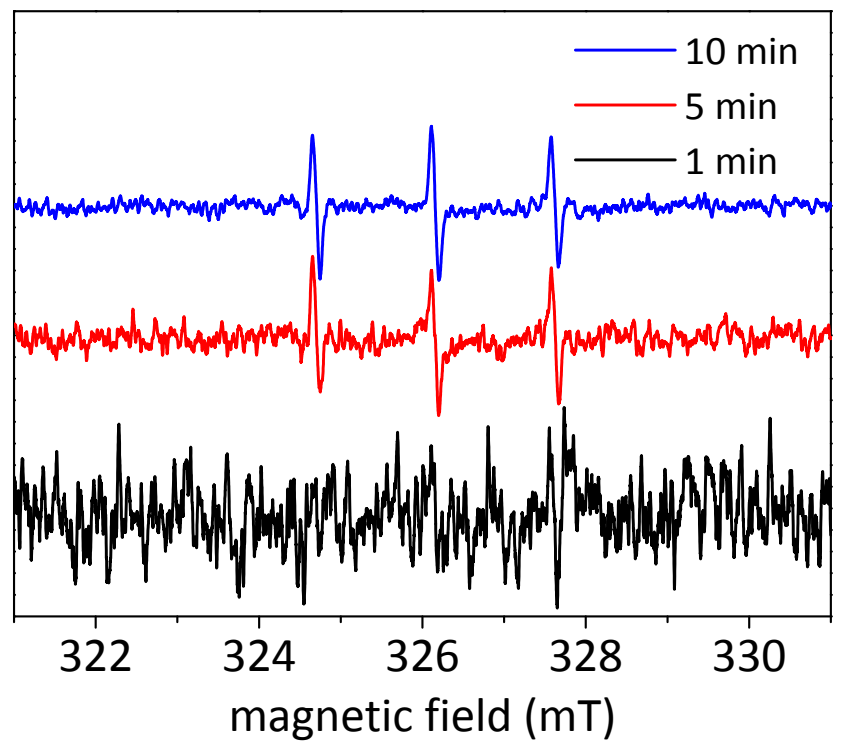

Fig. S15 ESR spectra with TEMP as spin trap for ${ }^{1} \mathrm{O}_{2}$ in the ES system. Initial conditions: cell voltage $=2 \mathrm{~V},[\mathrm{~S}(\mathrm{IV})]=1 \mathrm{mM},[\mathrm{TEMP}]=2.6 \mathrm{~g} \mathrm{~L}^{-1}$, $[$ phosphate buffer] $=10 \mathrm{mM}, \mathrm{pH} 7$. 


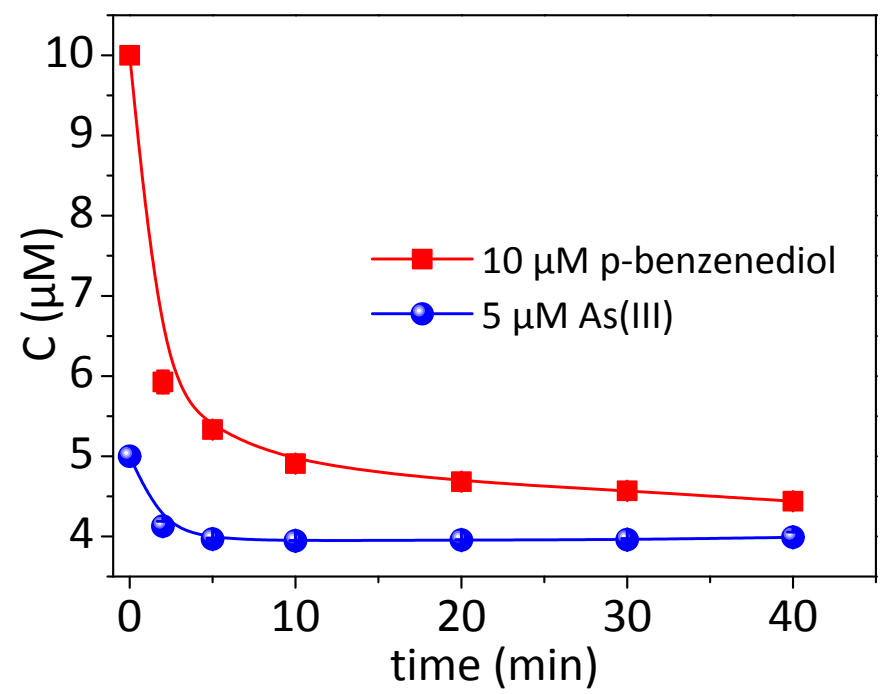

Fig. S16 Changes of $\mathrm{As}(\mathrm{III})$ and p-benzenediol concentrations in the $\mathrm{Fe}(\mathrm{III})-$ sulfite system in the presence of $\mathrm{N}$-hexanol. Initial conditions: $[\mathrm{Fe}(\mathrm{III})]=0.1$ $\mathrm{mM},[\mathrm{S}(\mathrm{IV})]=1 \mathrm{mM},[\mathrm{N}$-hexanol $]=5 \mathrm{mM},[\mathrm{p}$-benzenediol $]=10 \mu \mathrm{M},[\mathrm{As}(\mathrm{III})]=$ $5 \mu \mathrm{M}, \mathrm{pH} 7$.

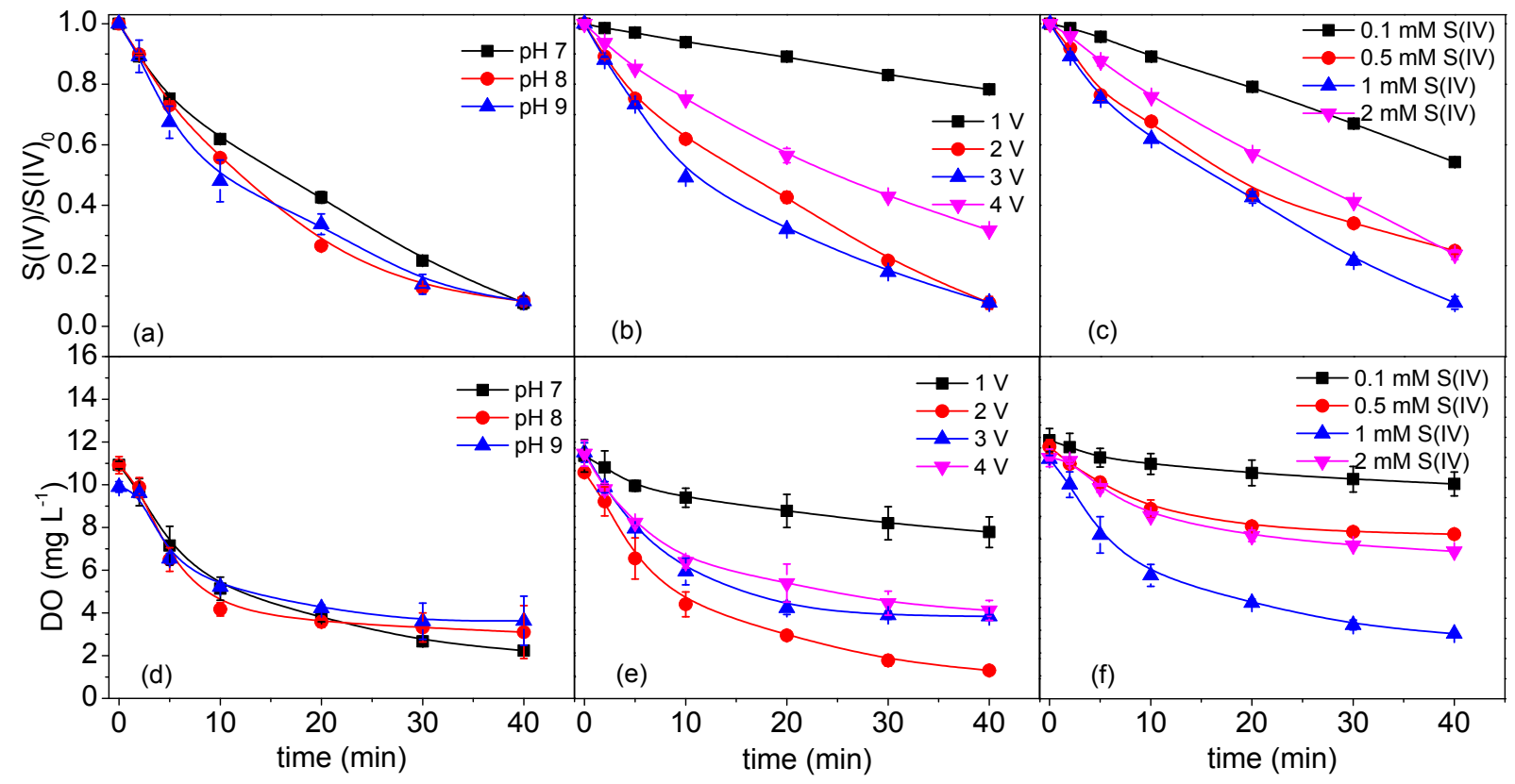

Fig. S17 Changes of S(IV) and DO concentrations in the ES process. Initial conditions: cell voltage $=1-4 \mathrm{~V},[\mathrm{~S}(\mathrm{IV})]=0.1-2 \mathrm{mM},[\mathrm{As}(\mathrm{III})]=5 \mu \mathrm{M},[$ phosphate , borate buffer] $=10 \mathrm{mM}, \mathrm{pH} \mathrm{7,} \mathrm{8,} 9$. 


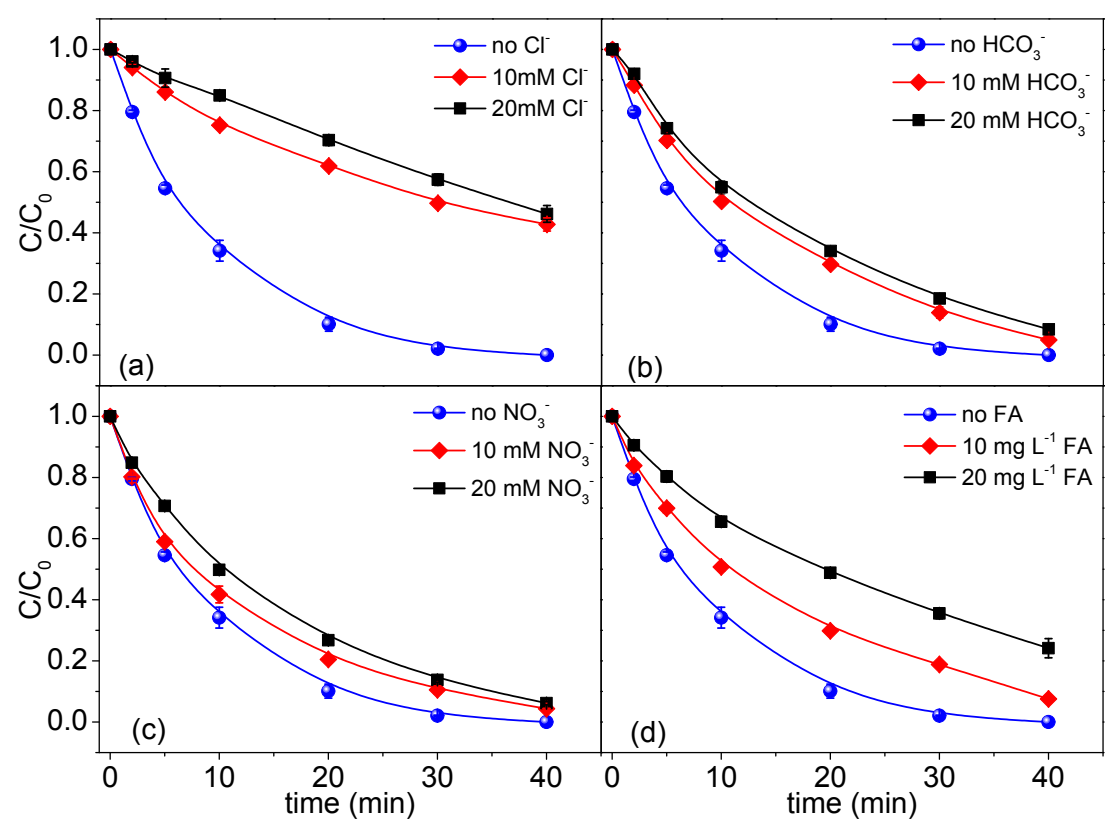

Fig. S18 Effect of matrix components on As(III) oxidation in the ES system.

Initial conditions: cell voltage $=2 \mathrm{~V},[\mathrm{~S}(\mathrm{IV})]=1 \mathrm{mM},[\mathrm{As}(\mathrm{III})]=5 \mu \mathrm{M},\left[\mathrm{Cl}^{-}, \mathrm{HCO}_{3}{ }^{-}\right.$, $\left.\mathrm{NO}_{3}^{-}\right]=10,20 \mathrm{mM},[\mathrm{FA}]=10,20 \mathrm{mg} \mathrm{L}^{-1}$, [phosphate buffer] $=10 \mathrm{mM}, \mathrm{pH} 7$.

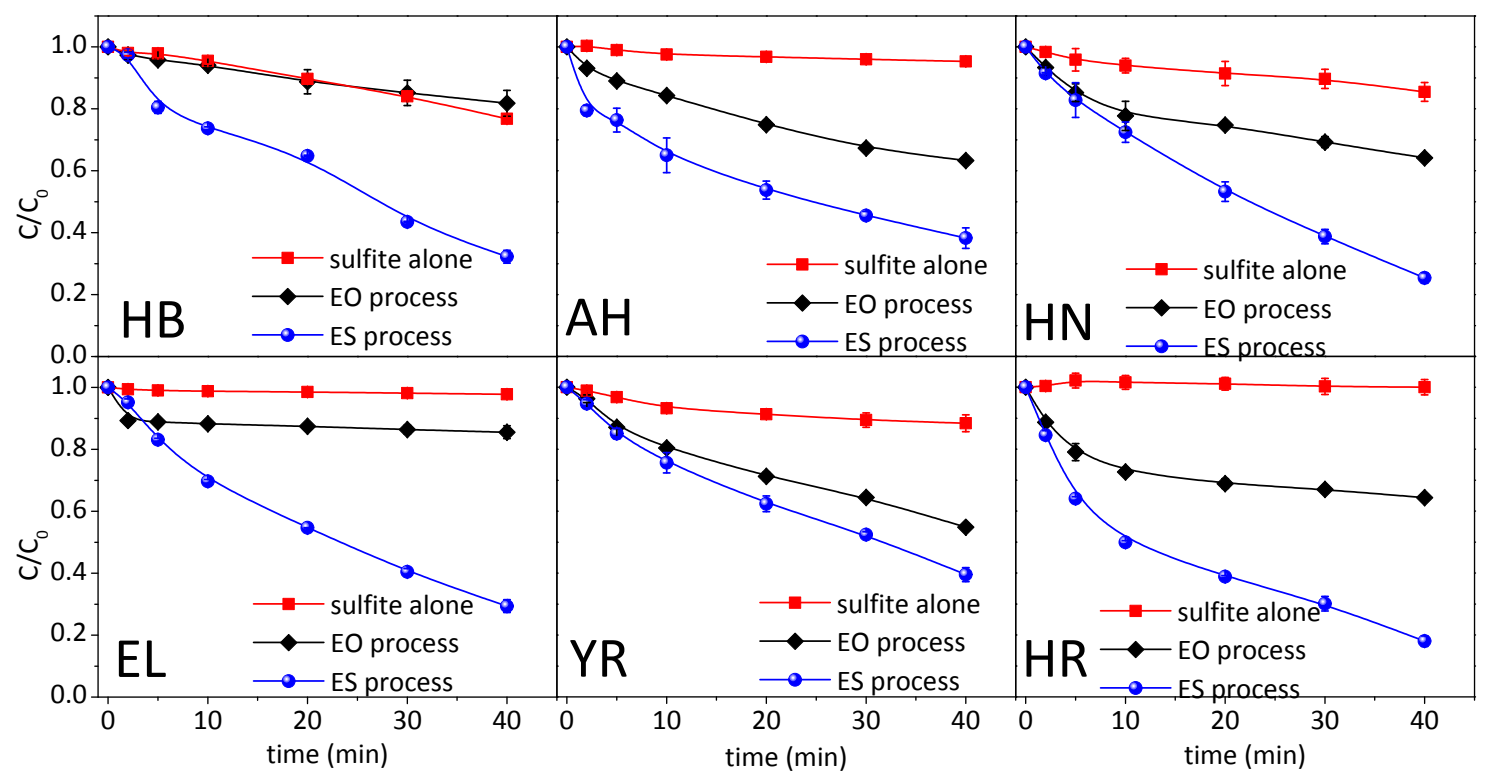

Fig. S19 As(III) oxidation in real field waters using the ES process. Initial conditions: cell voltage $=2 \mathrm{~V},[\mathrm{~S}(\mathrm{IV})]=1 \mathrm{mM},[\mathrm{As}(\mathrm{III})]=5 \mu \mathrm{M}, \mathrm{pH} 7$. 


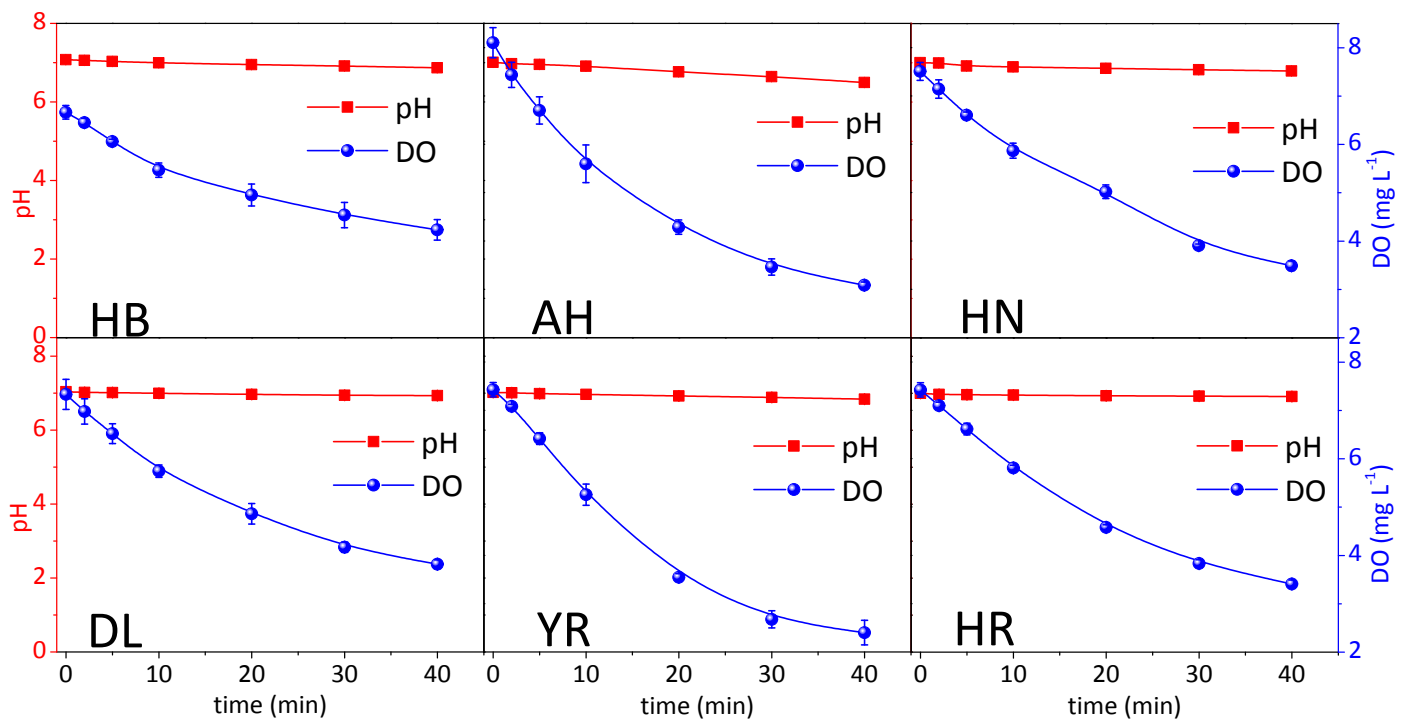

Fig. S2O Changes of $\mathrm{pH}$ and $\mathrm{DO}$ concentration in the real field waters in the ES process. Initial conditions: cell voltage $=2 \mathrm{~V},[\mathrm{~S}(\mathrm{IV})]=1 \mathrm{mM},[\mathrm{As}(\mathrm{III})]=5 \mu \mathrm{M}$, $\mathrm{pH} 7$.

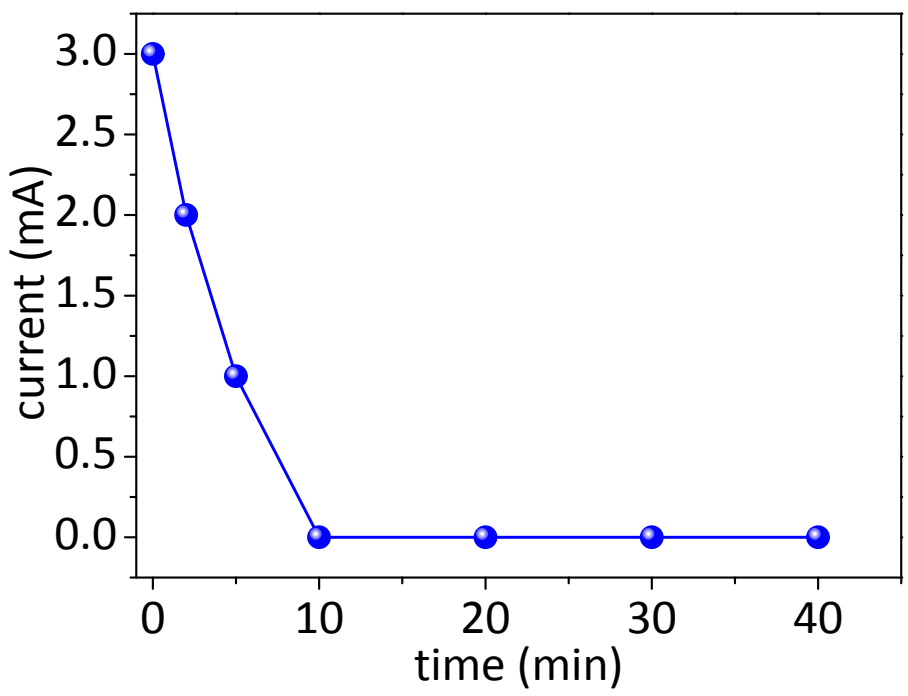

Fig. S21 Changes of current in the ES process. Initial conditions: cell voltage $=$ $2 \mathrm{~V},[\operatorname{As}(\mathrm{III})]=5 \mu \mathrm{M},[\mathrm{S}(\mathrm{IV})]=1 \mathrm{mM},[$ phosphate buffer $]=10 \mathrm{mM}, \mathrm{pH}$. The current is below $1 \mathrm{~mA}$ after $10 \mathrm{~min}$, which appeared as $0 \mathrm{~mA}$. 
Table S1 Characterizations of the field water samples.

\begin{tabular}{|c|c|c|c|c|c|c|}
\hline & \multicolumn{3}{|c|}{ Groundwater } & \multicolumn{3}{|c|}{ Surface water } \\
\hline & $\mathrm{HB}$ & $\mathrm{AH}$ & $\mathrm{HN}$ & $\overline{E L}$ & YR & $\mathrm{HR}$ \\
\hline \multirow{2}{*}{ GPS } & 311'17'"; & $30^{\circ} 5^{\prime} 38^{\prime \prime} ;$ & $31^{\circ} 52^{\prime} 23^{\prime \prime}$; & 30³3'6"; & $30^{\circ} 32^{\prime} 42^{\prime \prime} ;$ & $30^{\circ} 33^{\prime} 58^{\prime \prime} ;$ \\
\hline & $112^{\circ} 9^{\prime} 53^{\prime \prime}$ & $116^{\circ} 26^{\prime} 37^{\prime \prime}$ & $115^{\circ} 10^{\prime} 24^{\prime \prime}$ & $114^{\circ} 22^{\prime} 21^{\prime \prime}$ & $114^{\circ} 17^{\prime} 13^{\prime \prime}$ & $114^{\circ} 15^{\prime} 33^{\prime \prime}$ \\
\hline $\mathrm{pH}$ & 7.27 & 7.13 & 7.2 & 7.68 & 7.79 & 7.74 \\
\hline TOC & 14.4 & 4.8 & 10.8 & 8.3 & 6.9 & 7.5 \\
\hline $\mathrm{Cl}^{-}$ & 114.3 & 19.5 & 38.9 & 37.4 & 15.4 & 14.2 \\
\hline $\mathrm{NO}_{3}^{-}$ & 14.4 & 49.5 & 33.8 & 1.9 & 7.2 & 5.0 \\
\hline $\mathrm{HCO}_{3}{ }^{-}$ & 366 & 31 & 397 & 140 & 130 & 165 \\
\hline $\mathrm{PO}_{4}{ }^{3-}$ & ND & 0.133 & 0.244 & ND & ND & ND \\
\hline $\mathrm{Fe}$ & $\sim 0.01$ & $\sim 0.01$ & $\sim 0.01$ & $\sim 0.01$ & $\sim 0.01$ & $\sim 0.01$ \\
\hline $\mathrm{Mn}$ & ND & ND & ND & ND & ND & ND \\
\hline Co & ND & ND & ND & ND & ND & ND \\
\hline $\mathrm{Cu}$ & ND & ND & ND & ND & ND & ND \\
\hline $\mathrm{Ca}$ & 132.5 & 14.2 & 56.3 & 37.9 & 35.1 & 41.5 \\
\hline
\end{tabular}

Unit of concentration is $\mathrm{mg} \mathrm{L}^{-1}$, except for $\mathrm{pH}$.

Samples were filtered with $0.22 \mu \mathrm{m}$ mircopore membrane before TOC measurement.

$\mathrm{Cl}^{-}, \mathrm{NO}_{3}{ }^{-}$, and $\mathrm{PO}_{4}{ }^{3-}$ were determined by ion chromatography.

$\mathrm{HCO}_{3}{ }^{-}$concentration was determined by titration with $\mathrm{HCl}$.

Metal ions were determined by ICP-AES.

ND (Not detected) means that concentration is below the detect limit.

HB: Hubei province; $\mathrm{AH}$ : Anhui province; HN: Henan province; EL: East lake;

YR: Yangtze river; HR: Han river. 
Table S2 Reactions among reactive species, As(III), and scavengers and their second-order rate constant $\left(k, \mathrm{M}^{-1} \mathrm{~s}^{-1}\right)$ at specific $\mathrm{pH}$.

\begin{tabular}{|c|c|c|c|}
\hline No. & Reaction & $k$ & Ref. \\
\hline 1 & $\mathrm{As}(\mathrm{OH})_{3}+\mathrm{HO}^{\bullet} \rightarrow \mathrm{As}(\mathrm{OH})_{4}$ & $8.5 \times 10^{9}$ & 11 \\
\hline 2 & $\mathrm{As}(\mathrm{III})+\mathrm{SO}_{4}^{--} \rightarrow \mathrm{As}(\mathrm{IV})+\mathrm{SO}_{4}^{2-}$ & $6.1 \times 10^{9}$ & 11 \\
\hline 3 & $\mathrm{As}(\mathrm{III})+\mathrm{SO}_{5}^{--} \rightarrow \mathrm{As}(\mathrm{IV})+\mathrm{SO}_{4}^{2-}$ & $1.2 \times 10^{6}$ & this work \\
\hline 4 & $\mathrm{SO}_{3}^{2-}+2 \mathrm{OH}^{-} \rightarrow \mathrm{H}_{2} \mathrm{O}+\mathrm{e}^{-}+\mathrm{SO}_{4}^{2-}$ & - & 12 \\
\hline 5 & $\mathrm{HSO}_{3}^{-}+\mathrm{H}_{2} \mathrm{O} \rightarrow 3 \mathrm{H}^{+}+\mathrm{SO}_{4}^{2-}+2 \mathrm{e}^{-}$ & - & 12 \\
\hline 6 & $\mathrm{SO}_{3}^{\cdot-+}+\mathrm{O}_{2} \rightarrow \mathrm{SO}_{5}^{\cdot-}$ & $1.5 \times 10^{2}$ & 13 \\
\hline 7 & $\mathrm{SO}_{5}{ }^{--}+\mathrm{SO}_{3}^{2-} \rightarrow \mathrm{SO}_{4}^{--}+\mathrm{SO}_{4}^{2-}$ & $10^{4}-10^{7}$ & 14 \\
\hline 8 & $\mathrm{SO}_{4}^{\cdot-}+\mathrm{H}_{2} \mathrm{O} \rightarrow \mathrm{HO}+\mathrm{SO}_{4}^{2-}$ & $6.6 \times 10^{2}$ & 15 \\
\hline 9 & $\mathrm{SO}_{4}^{--}+\mathrm{HO}^{-} \rightarrow \mathrm{HO}+\mathrm{SO}_{4}^{2-}$ & $7.3 \times 10^{7}$ & 16 \\
\hline 10 & $\mathrm{SO}_{4}{ }^{--}+\mathrm{SO}_{3}^{2-} \rightarrow \mathrm{SO}_{3}^{\cdot-}+\mathrm{SO}_{4}^{2-}$ & $5.7 \times 10^{8}$ & 17 \\
\hline 11 & $\mathrm{HO}+\mathrm{SO}_{3}^{2-} \rightarrow \mathrm{SO}_{3}^{\cdot-}+\mathrm{OH}^{-}$ & $5.1 \times 10^{9}$ & 18 \\
\hline 12 & $\mathrm{H}_{2} \mathrm{O}_{2}+\mathrm{SO}_{3}^{2-} \rightarrow \mathrm{SO}_{4}^{2-}+\mathrm{H}_{2} \mathrm{O}$ & - & 19 \\
\hline 13 & $\mathrm{H}_{2} \mathrm{O}_{2}+\mathrm{SO}_{4}^{\cdot-} \rightarrow \mathrm{HO}_{2}^{\cdot}+\mathrm{SO}_{4}^{2-}+\mathrm{H}^{+}$ & $1.2 \times 10^{7}$ & 20 \\
\hline 14 & $\mathrm{H}_{2} \mathrm{O}_{2}+\mathrm{HO}^{\cdot} \rightarrow \mathrm{H}_{2} \mathrm{O}+\mathrm{O}_{2}^{\cdot-}+\mathrm{H}^{+}$ & $2.4 \times 10^{7}$ & 21 \\
\hline 15 & $\mathrm{SOD}+\mathrm{HO} \cdot \rightarrow$ products & $5.3 \times 10^{10}$ & 22 \\
\hline 16 & $\mathrm{EtOH}+\mathrm{SO}_{4}^{--} \rightarrow \mathrm{CH}_{3} \mathrm{CHOH}+\mathrm{SO}_{4}^{2-}$ & $5.6 \times 10^{7}$ & 17 \\
\hline 17 & $\mathrm{EtOH}+\mathrm{HO} \cdot \rightarrow \mathrm{H}_{2} \mathrm{O}+\mathrm{CH}_{3} \mathrm{CHOH}$ & $1.9 \times 10^{9}$ & 23 \\
\hline 18 & $\mathrm{TBA}+\mathrm{SO}_{4}{ }^{--} \rightarrow \cdot \mathrm{CH}_{2} \mathrm{C}\left(\mathrm{CH}_{3}\right)_{2} \mathrm{OH}+\mathrm{SO}_{4}^{2-}+\mathrm{H}^{+}$ & $9.1 \times 10^{5}$ & 4 \\
\hline 19 & $\mathrm{TBA}+\mathrm{HO} \cdot \rightarrow \mathrm{H} 2 \mathrm{O}+{ }^{\circ} \mathrm{CH}_{2} \mathrm{C}\left(\mathrm{CH}_{3}\right)_{2} \mathrm{OH}$ & $7.6 \times 10^{8}$ & 24 \\
\hline 20 & $\mathrm{SOD}+\mathrm{O}_{2}^{--} \rightarrow$ products & $1.6 \times 10^{9}$ & 25 \\
\hline 21 & $\mathrm{O}_{2}+\mathrm{H}^{+}+\mathrm{e}^{-} \rightarrow \mathrm{HO}_{2}^{\cdot}$ (cathode) & - & 26 \\
\hline
\end{tabular}




\begin{tabular}{|c|c|c|c|}
\hline 22 & $\mathrm{HO}_{2}^{\cdot}+\mathrm{H}^{+}+\mathrm{e}^{-} \rightarrow \mathrm{H}_{2} \mathrm{O}_{2}$ (cathode) & - & 26 \\
\hline 23 & $\mathrm{H}_{2} \mathrm{O}_{2} \rightarrow \mathrm{HO}_{2}^{\cdot}+\mathrm{H}^{+}+\mathrm{e}^{-}$(anode) & - & 26 \\
\hline 24 & $\mathrm{HO}_{2}^{\cdot} \rightarrow \mathrm{H}^{+}+\mathrm{e}^{-}+\mathrm{O}_{2}$ (anode) & - & 26 \\
\hline 25 & $\mathrm{H}_{2} \mathrm{O} \rightarrow \mathrm{H}_{2}+{ }^{1} \mathrm{O}_{2}$ or ${ }^{3} \mathrm{O}_{2}$ & - & this work \\
\hline 26 & FFA $+{ }^{1} \mathrm{O}_{2} \rightarrow$ products & $1.4 \times 10^{8}$ & 27 \\
\hline 27 & $\mathrm{FFA}+\mathrm{HO}^{\cdot} \rightarrow$ addition & $1.5 \times 10^{10}$ & 28 \\
\hline 28 & $\mathrm{Cl}^{-}+\mathrm{SO}_{4}{ }^{--} \rightarrow \mathrm{Cl} \cdot+\mathrm{SO}_{4}{ }^{2-}$ & $3.1 \times 10^{8}$ & 16 \\
\hline 29 & $\cdot \mathrm{OH}+\mathrm{Cl}^{-} \rightarrow \mathrm{ClOH}^{-}$ & $4.3 \times 10^{9}$ & 29 \\
\hline 30 & $\mathrm{ClOH}^{-}+\mathrm{H}^{+} \rightarrow \mathrm{Cl} \cdot+\mathrm{H}_{2} \mathrm{O}$ & $2.1 \times 10^{10}$ & 29 \\
\hline 31 & $\mathrm{HCO}_{3}^{-}+\mathrm{SO}_{4}^{\cdot-} \rightarrow \mathrm{CO}_{3}^{--}+\mathrm{SO}_{4}^{2-}+\mathrm{H}^{+}$ & $2.8 \times 10^{6}$ & 30 \\
\hline 32 & $\mathrm{HCO}_{3}^{-}+\mathrm{HO}^{\cdot} \rightarrow \mathrm{H}_{2} \mathrm{O}+\mathrm{CO}_{3}^{\cdot-}$ & $8.5 \times 10^{6}$ & 31 \\
\hline 33 & $\mathrm{NO}_{3}^{-}+\mathrm{SO}_{4}^{\cdot-} \rightarrow \mathrm{SO}_{4}^{2-}+\mathrm{NO}_{3}^{\cdot-}$ & $1.1 \times 10^{5}$ & 32 \\
\hline
\end{tabular}

Table S3 Economic analysis based on EE/O index of different systems.

\begin{tabular}{|c|c|c|c|}
\hline System & EE/O (kWh L-1) & Conditions & Reference \\
\hline $\mathrm{UV}-\mathrm{H}_{2} \mathrm{O}_{2}$ & $4.56 \times 10^{-2}$ & $\begin{array}{l}\text { UVC lamp: } 40 \mathrm{~W} ; \mathrm{H}_{2} \mathrm{O}_{2}: 0.125 \mathrm{mM} \text {; } \\
\text { oxidation efficiency: } 99 \% \text {; reaction } \\
\text { time: } 15 \mathrm{~min} ; \mathrm{pH} \text { 5.6-6.7. }\end{array}$ & 7 \\
\hline $\begin{array}{l}\text { UVC- } \\
\text { sulfite }\end{array}$ & $1.4 \times 10^{-2}$ & $\begin{array}{l}\text { UVC lamp: } 5 \mathrm{~W} \text {; sulfite: } 2 \mathrm{mM} \text {; } \\
\text { oxidation efficiency: } 50 \% \text {; reaction } \\
\text { time: } 10 \mathrm{~min} ; \mathrm{pH} 7 .\end{array}$ & 8 \\
\hline US-PS & $1.5 \times 10^{-2}$ & $\begin{array}{l}\text { US power: } 36 \mathrm{~W} \text {; PS: } 0.2 \mathrm{mM} \text {; } \\
\text { oxidation efficiency: } 99 \% \text {; reaction } \\
\text { time: } 10 \mathrm{~min} ; \mathrm{pH} 7 .\end{array}$ & 9 \\
\hline EO & $2.5 \times 10^{-4}$ & $\begin{array}{l}\text { SSN anode, RGO@SSN cathode; } \\
\text { cell voltage: } 2.5 \mathrm{~V} \text {; current: } 20 \mathrm{~mA} \text {; } \\
\text { oxidation efficiency: } 40 \% \text {; reaction } \\
\text { time: } 60 \mathrm{~min} \text {; } \mathrm{pH} 7.2 \text {. }\end{array}$ & 10 \\
\hline EO & $2.6 \times 10^{-5}$ & $\begin{array}{l}\text { Graphite anode, graphite cathode; } \\
\text { cell voltage: } 2 \mathrm{~V} \text {; current: } 1.5 \mathrm{~mA} \text {; } \\
\text { oxidation efficiency: } 30 \% \text {; reaction } \\
\text { time: } 40 \mathrm{~min} ; \mathrm{pH} 7 \text {. }\end{array}$ & This work \\
\hline ES & $2.0 \times 10^{-6}$ & $\begin{array}{l}\text { Graphite anode, graphite cathode; } \\
\text { cell voltage: } 2 \mathrm{~V} \text {; current: } 1.5 \mathrm{~mA} \text {; } \\
\text { sulfite: } 1 \mathrm{mM} \text {; oxidation efficiency: } \\
99 \% \text {; reaction time: } 40 \mathrm{~min} ; \mathrm{pH} 7 .\end{array}$ & This work \\
\hline
\end{tabular}




\section{References}

(1) Ronzani, F.; Trivella, A.; Arzoumanian, E.; Blanc, S.; Sarakha, M.; Richard, C.; Oliveros, E.; Lacombe, S. Comparison of the photophysical properties of three phenothiazine derivatives: transient detection and singlet oxygen production. Photochem. Photobiol. Sci. 2013, 12 (12), 2160-2169.

(2) Bokare, A. D.; Choi, W. Singlet-oxygen generation in alkaline periodate solution. Environ. Sci. Technol. 2015, 49 (24), 14392-14400.

(3) Yu, Y.; Zhou, D.; Wu, F. Mechanism and products of the photolysis of hexabromocyclododecane in acetonitrile-water solutions under a UV-C lamp. Chem. Eng. J. 2015, 281, 892-899.

(4) Zhou, D.; Yuan, Y.; Yang, S.; Gao, H.; Chen, L. Roles of oxysulfur radicals in the oxidation of acid orange 7 in the $\mathrm{Fe}(\mathrm{III})-$ sulfite system. J. Sulfur Chem. 2015, $36(4), 373-384$.

(5) Huie, R. E.; Neta, P. One-electron redox reactions in aqueous solutions of sulfite with hydroquinone and other hydroxyphenols. J. Phys. Chem. 1985, 89 (18), 3918-3921.

(6) Sun, P.; Tyree, C.; Huang, C. H. Inactivation of escherichia coli, bacteriophage $\mathrm{MS} 2$, and bacillus spores under $\mathrm{UV} / \mathrm{H}_{2} \mathrm{O}_{2}$ and UV/peroxydisulfate advanced disinfection conditions. Environ. Sci. Technol. 2016, 50 (8), 4448-4458. 
(7) Lescano, M.; Zalazar, C.; Cassano, A.; Brandi, R. Kinetic modeling of arsenic (III) oxidation in water employing the $\mathrm{UV} / \mathrm{H}_{2} \mathrm{O}_{2}$ process. Chem. Eng. J. 2012, 211-212, 360-368.

(8) Luo, T.; Wang, Z.; Wang, Y.; Liu, Z.; Pozdnyakov, I. P. Different role of bisulfite/sulfite in UVC-S(IV)- $\mathrm{O}_{2}$ system for arsenite oxidation in water. Molecules 2019, 24, 2307.

(9) Neppolian, B.; Doronila, A.; Ashokkumar, M. Sonochemical oxidation of arsenic(III) to arsenic(V) using potassium peroxydisulfate as an oxidizing agent. Water Res. 2010, 44 (12), 3687-3695.

(10) Li, X.; Liu, F.; Zhang, W.; Lu, H.; Zhang, J. Electrocatalytical oxidation of arsenite by reduced graphene oxide via in-situ electrocatalytic generation of $\mathrm{H}_{2} \mathrm{O}_{2}$. Environ. Pollut. 2019, 254, 112958.

(11) Xu, J.; Ding, W.; Wu, F.; Mailhot, G.; Zhou, D.; Hanna, K. Rapid catalytic oxidation of arsenite to arsenate in an iron(III)/sulfite system under visible light. Appl. Catal. B Environ. 2016, 186, 56-61.

(12) Hunger, T.; Lapicque, F. Electrochemistry of the Oxidation of Sulfite and Bisulfite lons at a Graphite Surface: An Overall Approach. Electrochim. Acta 1991, 36, 1073-1082.

(13) Huie, R. E.; Neta, P. Chemical behavior of $\mathrm{SO}_{3}{ }^{-}$and $\mathrm{SO}_{5}{ }^{-}$radicals in aqueous solutions. J. Phys. Chem. 1984, 88 (11), 5665-5669.

(14) Kuo, D. T. F.; Kirk, D. W.; Jia, C. Q. The chemistry of aqueous S(IV)-Fe$\mathrm{O}_{2}$ system: state of the art. J. Sulfur Chem. 2006, 27 (5), 461-530. 
(15) Herrmann, H.; Reese, A.; Zellner, R. Time-resolved UV/vis diode array absorption spectroscopy of $\mathrm{SOx}-(X=3,4,5)$ radical anions in aqueous solution. J. Mol. Struct. 1995, 348 (2), 183-186.

(16) Chawla, O. P.; Fessenden, R. W. Electron spin resonance and pulse radiolysis studies of some reactions of $\mathrm{SO}_{4}{ }^{--}$. J. Phys. Chem. 2005, 79 (24), 2693-2700.

(17) Deister, U.; Warneck, P. Photooxidation of $\mathrm{SO}_{3}^{2-}$ in aqueous solution. J. Phys. Chem. 1990, 94, 2191-2198.

(18) Huie, R. E.; Neta, P. Rate constants for some oxidations of S(IV) by radicals in aqueous solutions. Atmos. Environ. 1987, 21 (8), 1743-1747.

(19) Manaka, A.; Igarashi, S. Simple Determination of trace amounts of antigen using autocatalytic reaction with $\mathrm{Na}_{2} \mathrm{SO}_{3}$ and $\mathrm{H}_{2} \mathrm{O}_{2}$ followed by enzyme immunoassay. Anal. Lett. 2003, 36 (1), 135-144.

(20) Maruthamuthu, P.; Neta, P. Phosphate radicals. spectra, acid-base equilibria, and reactions with inorganic compounds. J. Phys. Chem. 1978, 82 (6), 710-713.

(21) Merényi, G.; Lind, J. S. Role of a peroxide intermediate in the chemiluminescence of luminol. a mechanistic study. J. Am. Chem. Soc. 1980, $102(18), 5830-5835$.

(22) Roberts, P. B.; Fielden, E. M.; Rotilio, G.; Calabrese, L.; Bannister, J. V.; Bannister, W. H. Superoxide dismutase inactivation by radiation-induced radicals: evidence for histidine residues in the active site. Radiat. Res. 1974, 
$60(3), 441-452$.

(23) Matheson, M. S.; Mamou, A.; Silverman, J.; Rabani, J. Reaction of hydroxyl radicals with polyethylene oxide in aqueous solution. J. Phys. Chem. $1973,77,2420-2424$.

(24) Gordon, S.; Schmidt, K. H.; Hart, E. J. A pulse radiolysis study of aqueous benzene solutions. J. Phys. Chem. 1977, 81 (2), 104-109.

(25) Luchinat, C.; Bielski, B. H. J.; Cabelli, D. E.; Banci, L.; Bertini, I.; Mullenbach, G. T.; Hallewell, R. A. An investigation of a human erythrocyte sod modified at position 137. J. Am. Chem. Soc. 1989, 111 (2), 714-719.

(26) Zhou, W.; Rajic, L.; Chen, L.; Kou, K.; Ding, Y.; Meng, X.; Wang, Y.; Mulaw, B.; Gao, J.; Qin, Y.; Alshawabkeh, A. N. Activated carbon as effective cathode material in iron-free electro-fenton process: integrated $\mathrm{H}_{2} \mathrm{O}_{2}$ electrogeneration, activation, and pollutants adsorption. Electrochim. Acta 2019, 296, 317-326.

(27) Gottfried, V.; Kimel, S. Temperature effects on photosensitized processes. J. Photochem. Photobiol. B Biol. 1991, 8 (4), 419-430.

(28) Savel'eva, O.; Shevchuk, L.; Vysotskaya, N. . Reactivity of substituted benzenes, furans, and pyridines to hydroxyl radicals. J. Org. Chem. USSR 1973, $9,759-761$.

(29) Jayson, G. G.; Parsons, B. J.; Swallow, A. J. Some simple, highly reactive, inorganic chlorine derivatives in aqueous solution. React. Inorg. Chlorine Deriv. 1973, 69, 1597-1607.

(30) Huie, R. E.; Clifton, C. L. Temperature dependence of the rate constants 
for reactions of the sulfate radical, $\mathrm{SO}_{4}{ }^{-}$, with anions. J. Phys. Chem. 1990, 94 (23), 8561-8567.

(31) Buxton, G. V; Elliott, A. J. Rate constant for reaction of hydroxyl radicals with bicarbonate ions. Radiat. Phys. Chem. 1986, 27 (3), 241-243.

(32) Wine, P. H.; Mauldin, R. L.; Thorn, R. P. Kinetics and spectroscopy of the nitrogen oxide radical $\left(\mathrm{NO}_{3}{ }^{-}\right)$in aqueous ceric nitrate-nitric acid solutions. $\mathrm{J}$. Phys. Chem. 2005, 92 (5), 1156-1162. 